\title{
Value of systolic and diastolic time intervals Studies in normotensive and hypertensive 50-year-old men and in patients after myocardial infarction
}

\author{
JOHN WIKSTRAND, GÖRAN BERGLUND, LARS WILHELMSEN, AND \\ INGEMAR WALLENTIN
}

From the Department of Clinical Physiology and the Section of Preventive Cardiology, Department of Medicine I, Sahlgren's Hospital, University of Göteborg, Sweden

SUMMARY Systolic and diastolic time intervals were studied non-invasively in a group of untreated hypertensives $(n=19)$ and a reference group $(n=36)$, all derived from a random population sample of 50-year-old men, and in a myocardial infarct group $(n=67)$ representative of men aged 48 to 57 years surviving infarction. The results showed that only the electromechanical interval, pressure rise velocity, and the interval between the aortic component of the second heart sound $\left(\mathrm{A}_{2}\right)$ and the O-point in the apex cardiogram were useful discriminants between the three groups. There were no significant differences in systolic time intervals between the groups and the systolic time intervals were of limited diagnostic value as signs of impaired left ventricular function.

The infarct patients had a significantly longer electromechanical interval $(34 \mathrm{~ms})$ than individuals in the reference group ( $27 \mathrm{~ms}$ ), indicating delayed start of the systolic contraction in the infarction group. The pre-ejection period predicted the isovolumetric contraction time with great uncertainty in the infarct group.

Increased pressure rise velocity (resting diastolic blood pressure/isovolumetric contraction time $\geqslant 1200 \mathrm{mmHg} / \mathrm{s}$ ) was seen in 38 per cent of the infarct patients and 67 per cent of the hypertensives, compared with 4 per cent in the reference group, indicating more powerful contraction in infarct patients and hypertensives as compared with subjects in the reference group. The difference could not be explained by a difference in preload as judged from the a-wave in the apex cardiogram.

The $\mathrm{A}_{2} \mathrm{O}$ interval was significantly prolonged $(\geqslant 150 \mathrm{~ms})$ in 74 per cent of the infarct patients and 56 per cent of the hypertensives, as compared with 3 per cent in the reference group, indicating prolonged relaxation or prolongation of the early filling phase of the left ventricle in hypertensives and infarct patients. This was mainly related to factors other than heart rate and blood pressure.

Non-invasively derived systolic time intervals for assessment of left ventricular function such as the left ventricular ejection time (LVET) and the preejection period (PEP) have been extensively studied. PEP comprises the isovolumetric contraction time (ICT) and the interval from the beginning of depolarisation to the start of the systolic contraction, i.e. the electromechanical interval (EMI); it has been pointed out that the ICT should provide a better measure of left ventricular function than the PEP (Kumar and Spodick, 1970).

Prolongation of the PEP and shortening of the

Received for publication 25 February 1977
LVET with consequent prolongation of the PEP/LVET ratio have been ascribed to impaired contractility of the left ventricle. These changes in PEP and LVET have also been found to correlate well with contractility and measures of pump function (Garrard et al., 1970; Ahmed et al., 1972). Despite this, many authors have doubted the value of the systolic time intervals (Hodges et al., 1972; Parker and Just, 1974).

Several authors have used apex cardiography to measure the interval between the aortic component of the second heart sound $\left(A_{2}\right)$ and the $O$-point in the apex cardiogram in order to study isovolumetric relaxation (Tavel et al., 1965; Benchimol and Ellis, 
1967; Kumar and Spodick, 1970). Transducers with short low frequency time constants have often been used. These transducers, however, shorten the $\mathrm{A}_{2} \mathrm{O}$ interval and tend to smooth out differences between a prolonged and a normal $\mathrm{A}_{2} \mathrm{O}$ interval (Johnson et al., 1971; Wikstrand et al., 1977).

Most of the above-mentioned studies were carried out in small selected groups of hospital patients. The aim of the present study was to investigate the value of non-invasively registered time intervals in representative groups of untreated hypertensives and postinfarction patients, and to establish the normal limits for these intervals in 50-year-old men.

\section{Groups studied}

All subjects of a random population sample of 50year-old men in Göteborg, Sweden (Wilhelmsen et al., 1972), with untreated essential hypertension were allocated to a hypertensive group $(n=35)$. Essential hypertension was defined by casual blood pressure above $175 \mathrm{mmHg}$ systolic or $115 \mathrm{mmHg}$ diastolic on two separate occasions and a negative diagnostic examination for secondary hypertension (Wilhelmsen et al., 1973).

A reference group $(n=73)$ with casual blood pressure below $175 \mathrm{mmHg}$ systolic and $115 \mathrm{mmHg}$ diastolic was obtained from the same population by drawing a 10 per cent subsample at random. The way in which these groups were selected (Fig. 1, upper panel) has been described in detail elsewhere (Wikstrand et al., 1976). The infarct group $(n=67)$ consisted of men living in Göteborg, born between 1916 and 1924, who suffered a hospital verified myocardial infarction during a 12-month period (15 July 1972 to 14 July 1973 ) and survived for at least 3 months (Fig. 1, lower panel). The non-invasive investigations were carried out in a randomised half of the reference group $(n=36)$ and of the hypertension group $(n=19)$ (Fig. 1) and in all infarct patients $(n=67)$.

Sahlgren's Hospital takes care of practically all patients sustaining a myocardial infarct in Göteborg. Suspected cases of myocardial infarction were recorded by the staff responsible for the Myocardial Infarction Register in Göteborg. Acute myocardial infarction was considered to have occurred when at least two of the three criteria-central chest pain, transient rise of serum aspartate transaminase, or electrocardiographic abnormalities-were fulfilled. The patients so identified have been shown to constitute at least 90 per cent of the total number of surviving myocardial infarction patients in the population of Göteborg (Elmfeldt et al., 1975a). They were systematically cared for after discharge from hospital at the Post-Myocardial Infarction Clinic by physicians trained together to achieve a standardised treatment regimen (Elmfeldt et al., 1975b).

During an observation period of one year 100 acute myocardial infarcts were recorded. Before 31 December 1972, 18 patients were selected by means of a random number table to participate in another study. These patients were not followed up at the Post-Myocardial Infarction Clinic and were excluded from our study. Twelve patients died within three months of onset of infarction and two patients were excluded from the analysis, one because of mitral stenosis and one because of aortic valvular disease. One patient who had had a cerebrovascular stroke was unable to participate. The mean age for the infarct group was $53 \frac{1}{2}$ years (range 48 to 57). Fifty-nine patients had primary infarcts and 8 patients suffered from reinfarction. During the period of acute care in hospital 14 patients had signs of cardiogenic shock, defined as a systolic blood pressure below $100 \mathrm{mmHg}$ with cold sweaty skin, or left ventricular failure, defined as basal râles over the lungs persisting after cough or evidence of congestion on a chest $x$-ray film. At the time of the non-invasive examination 21 patients were on digitalis therapy, 7 on $\beta$-blockers, and a further 4 on both digitalis and $\beta$-blockers. Two years after the non-invasive investigation 9 of the patients in the infarct group had died from ischaemic heart disease, verified at necropsy in all cases.

\section{Methods}

Conventional electrocardiograms, carotid pulse tracings, apex cardiograms, phonocardiograms, and resting blood pressures were all recorded on a direct writing ink-jet 7-channel mingograph (EM 81, Siemens-Elema $A B$, Sweden) with a linear frequency response from 0 to $500 \mathrm{~Hz}$ and 30 per cent amplitude reduction at $650 \mathrm{~Hz}$. The phonocardiograms were recorded using a phonopreamplifier (EMT 22) with electrical filters that together with a piezoelectric microphone (EMT $25 \mathrm{C})$ gave six frequency ranges including one aural frequency range. The pulse tracings and apex cardiograms were obtained using crystal transducers (EMT $510 \mathrm{C}$ ) with low frequency time constants between 1.9 and $4.6 \mathrm{~s}$ (depending on a capacitanceresistance product, decided by the individual amplification used for each curve) and connected by a 25 to $40 \mathrm{~cm}$ rubber tube to a specially designed capillary-damped funnel pick-up, $2.5 \mathrm{~cm}$ in diameter, giving a frequency response of at least 0.08 (at low frequency time constant $1.9 \mathrm{~s}$ ) to $65 \mathrm{~Hz}$ (-3dB) (Wikstrand et al., 1977). The paper speed 

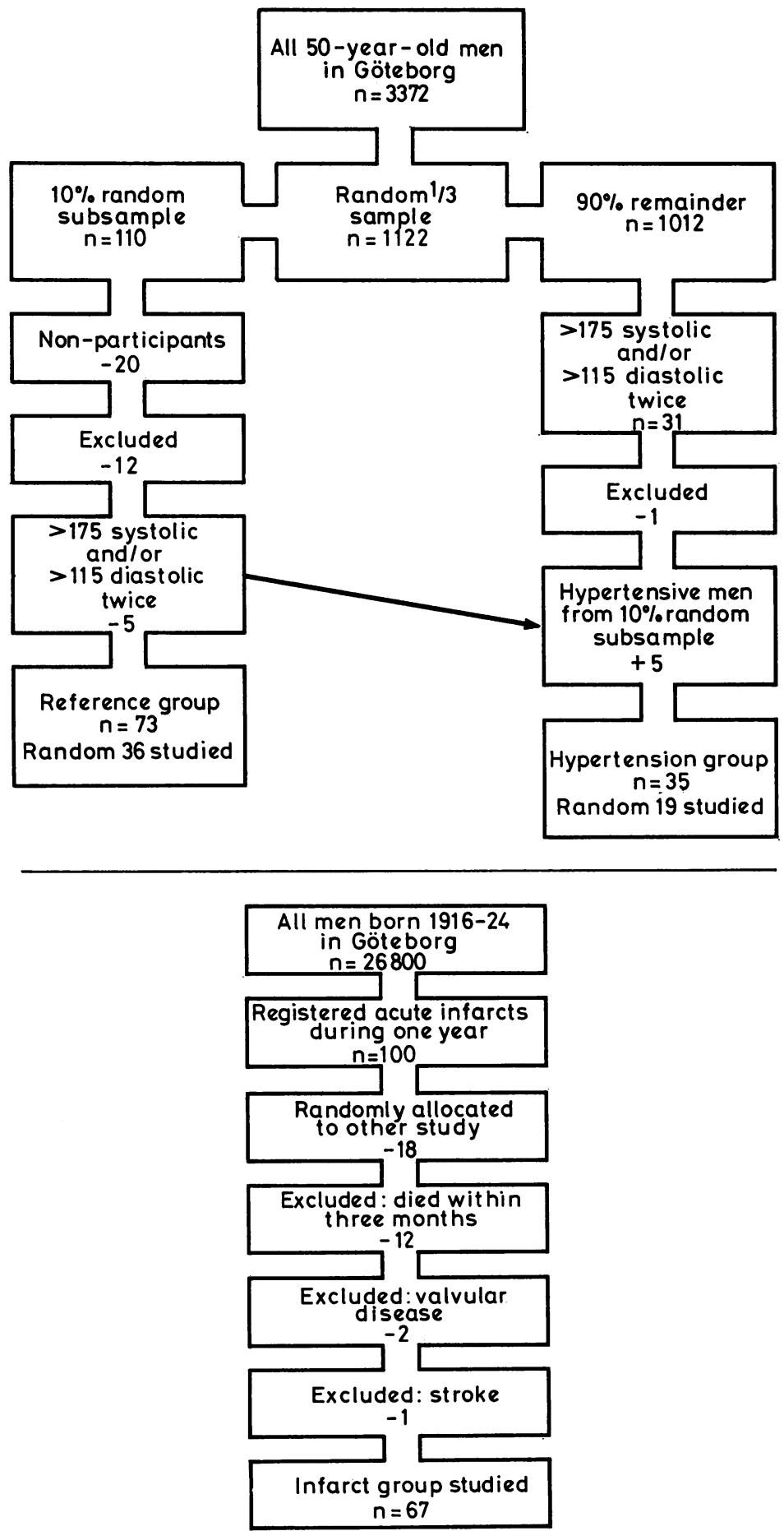

Fig. 1 Groups studied. Upper panel: schematic representation of the selection of the hypertensive and reference groups. Lower panel: schematic representation of how the infarction group was derived. 
was $50 \mathrm{~mm} / \mathrm{s}$ for the electrocardiogram and for the other tracings $100 \mathrm{~mm} / \mathrm{s}$.

Blood pressure was measured with a $12 \mathrm{~cm}$ broad and $26 \mathrm{~cm}$ long rubber cuff. Cuff inflation was rapid, cuff deflation approximately 3 beats/ $10 \mathrm{mmHg}$. Diastolic pressure was recorded as phase 5, i.e. when the sounds disappeared. Casual blood pressure at the screening examination was measured in the seated position with a mercury manometer and stethoscope. Resting blood pressure was measured after one hour's rest, during which the non-invasive tracings were recorded, in the supine position in a sound-protected room with an automatic device for cuff inflation and deflation (Boucke-Brecht), with a microphone (EMT 25 C) placed over the right brachial artery and with simultaneous recording of cuff pressure, Korotkoff sounds, and electrocardiogram. Resting blood pressure was, for technical reasons, lacking for 4 subjects in the reference group. Resting heart rate was measured from the resting blood pressure recordings.

Simultaneous recordings of electrocardiogram lead II, a phonocardiogram from the third left intercostal space parasternally, a carotid pulse tracing or apex cardiogram were recorded during the resting period preceding the measurement of resting blood pressure. The carotid pulse tracing was recorded in the supine position and the apex cardiogram in the left lateral position, both during relaxed expiratory apnoea.

Simultaneous recordings of the carotid pulse tracing, apex cardiogram, electrocardiogram lead II, and the phonocardiogram in the left lateral position were carried out in a randomised half of the reference group and in 56 infarct patients in order to perform regression analysis with ICT and heart rate, and ICT/LVET and heart rate. Except for the purpose of this correlation analysis, all data were obtained from recordings made separately.

All channels were corrected for coincidence, the deviations being calculated as the mean value of the difference in upstroke in 4 consecutive $\mathrm{mV}$ tests induced simultaneously in the 7 channels. Correction was also made for the time delay ( $4 \mathrm{~ms}$ ) in the recording system (Wikstrand et al., 1977). Definitions of the measurement points on the electrocardiogram, phonocardiogram, carotid pulse tracing, and apex cardiogram have been presented in detail elsewhere (Wikstrand, thesis 1976, available on request). The measurement points were determined in relation to 4 arbitrary reference lines (Fig. 2) and plotted on a stencil, the time interval being determined by addition of the various component intervals before, between, and after the reference lines which made up each individual time interval. This procedure was used in order to simplify the extensive calculations and to avoid bias by the observer when calculating consecutive beats. In each curve the time was obtained in $\mathrm{ms}$ by means of a simultaneously recorded stable time signal with one impulse/s calibrated with the aid of a time generator (Type 1192-B/Z, General Radio Company, USA). This time signal was used because the paper speed was not constant, probably because of fluctuations in the electricity supply to the equipment.

The time intervals studied (Fig. 2, lower panel) were as follows: (1) Total electromechanical systole from the beginning of the QRS complex to the beginning of the aortic component of the second heart sound $\left(\mathrm{QA}_{2}\right)$. In 2 infarct patients $\mathrm{A}_{2}$ could not be identified with certainty. (2) The electromechanical interval from the beginning of the QRS complex to the systolic upstroke of the apex cardiogram (EMI). ${ }^{1}$ In 4 subjects $(11 \%)$ in the reference group, 1 hypertensive subject (5\%), and 1 patient in the infarct group $(1.5 \%)$ an acceptable apex cardiogram could not be recorded, and in another 2 subjects in the reference group and 1 in the infarct group the upstroke of the apex cardiogram could not be identified with certainty. (3) The left ventricular ejection time from the beginning of the systolic upstroke of the carotid pulse tracing to the incisura (LVET). The LVET was also expressed as a percentage of the expected value for the given heart rate calculated from the regression equation between LVET and heart rate in the reference group (LVET\%). (4) The pre-ejection period $\left(\mathrm{PEP}=\mathrm{QA}_{2}-\mathrm{LVET}\right)$. (5) The isovolumetric contraction time (ICT =PEP-EMI). (6) The PEP/LVET ratio. (7) The ICT/LVET ratio. (8) The interval between $A_{2}$ and the point on the downstroke of the apex cardiogram at which the curve fell to 10 per cent of the total height of the curve $\left(\mathrm{A}_{2}-90 \%\right.$ amplitude reduction). (9) The interval between the aortic component of the second sound and the $O$-point of the apex cardiogram $\left(\mathrm{A}_{2} \mathrm{O}\right)$. In 3 subjects in the reference group the $\mathrm{O}$-point could not be identified with certainty.

In left bundle-branch block or $Q R S \geqslant 0.12 \mathrm{~s}$ (not caused by right bundle-branch block; Minnesota Code $7: 1$ or $7: 4$ ) in 1 hypertensive individual and 6 infarct patients the values for $\mathrm{QA}_{2}$ and $\mathrm{EMI}$ were not included in the distribution or mean values since these conduction defects cause delayed activation of the left ventricle (Baragan et al., 1968). The

${ }^{2}$ No significant difference was found between values of mean EMI calculated from recordings made separately and simultaneously. Measurements of EMI made by two independent observers from recordings obtained one hour apart agreed closely (correlation coefficient $0.91, \mathrm{n}=86$ ). 

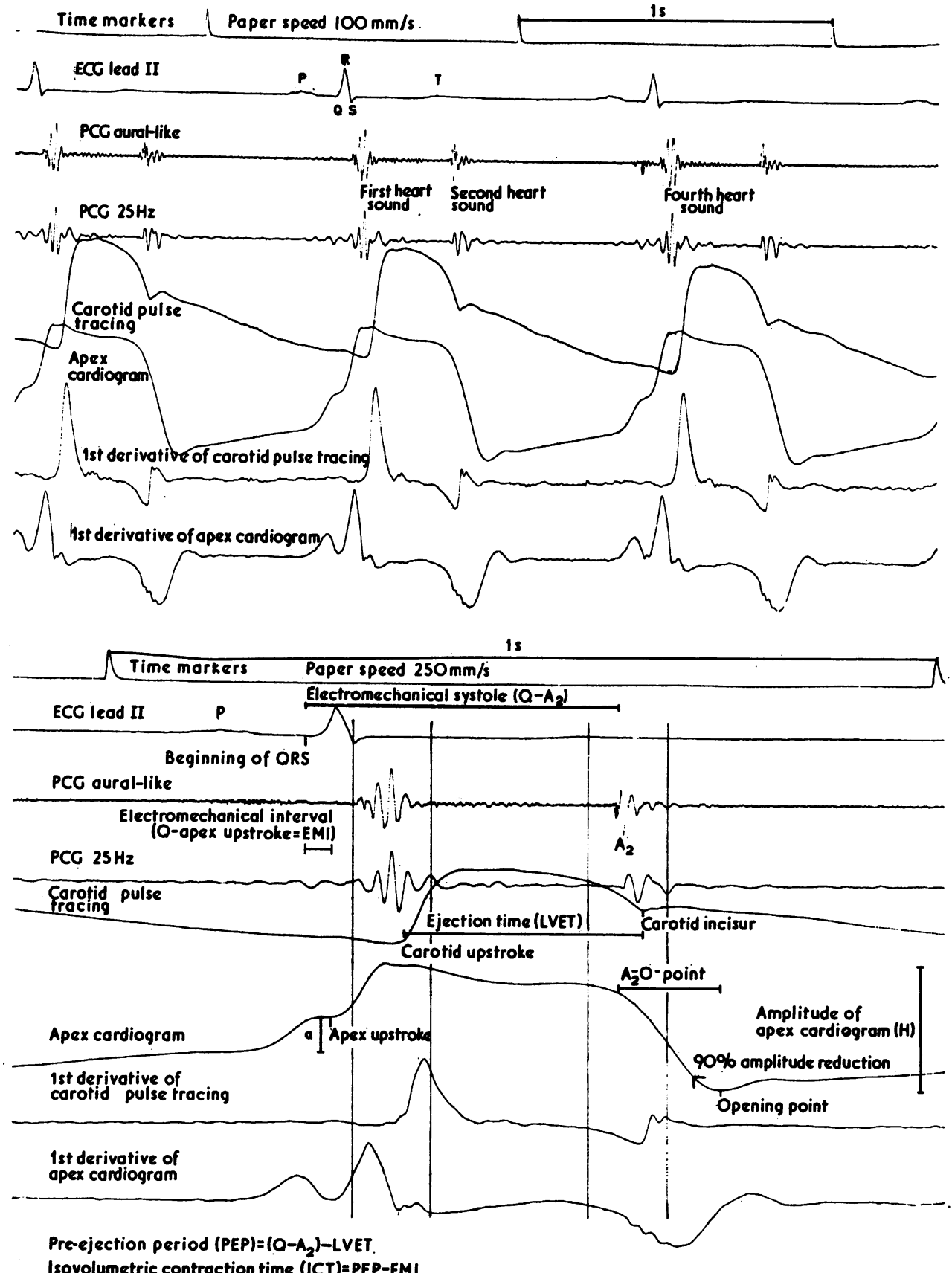

Fig. 2 Simultaneous recording of the apex cardiogram, carotid pulse tracing, phonocardiogram, and electrocardiogram in one of the infarct patients. Upper panel: paper speed $100 \mathrm{~mm} / \mathrm{s}$. Lower panel: time intervals are, for practical reasons, marked on this recording at a paper speed of $250 \mathrm{~mm} / \mathrm{s}$. Four reference lines (marked in lower panel) were used when the time intervals were measured (see Methods). The a-wave (a) and the total height $(H)$ of the apex cardiogram are also marked in the lower panel (abbreviations, see Methods). 
values have, however, been used for calculation of ICT (ICT $=\mathrm{QA}_{2}-\mathrm{EMI}-\mathrm{LVET}$ ).

The a-wave (a) percentage amplitude of the total deflection of the apex cardiogram $(\mathrm{H})$ was calculated.

Time intervals and the $\mathrm{a} / \mathrm{H}$ ratio were calculated as the mean of measurements from 5 consecutive beats.

An $\mathrm{a} / \mathrm{H}$ ratio above 15 per cent was considered abnormal (Voigt and Friesinger, 1970; Wikstrand et al., 1976). Limits for abnormal time intervals were arbitrarily set at the second highest or lowest value in the reference group, depending on whether a high or low value of the variable concerned was of pathological significance. If the two highest (or lowest) values in the reference group were identical, the limit was set at the highest (or lowest) value. On this basis pathological values were defined as: EMI $\geqslant 40 \mathrm{~ms}$, PEP $\geqslant 130 \mathrm{~ms}$, ICT $\geqslant 100 \mathrm{~ms}$, LVET $\leqslant 90$ per cent, ICT/LVET $>0 \cdot 35$, PEP/ LVET $>0.45, \mathrm{~A}_{2}$ to 90 per cent amplitude reduction $\geqslant 105 \mathrm{~ms}$, and $\mathrm{A}_{2} \mathrm{O} \geqslant 150 \mathrm{~ms}$. The diastolic resting blood pressure was divided by the ICT and in a corresponding manner a diastolic blood pressure/ICT $\leqslant 775 \mathrm{mmHg} / \mathrm{s}$ was defined as pathologically low. The limit for elevation of this variable was set at $1200 \mathrm{mmHg} / \mathrm{s}$.

Analysis of each variable was performed without knowledge of the results of the other examinations or to which group the subject belonged.

Standard methods were used for calculation of the mean $(\overline{\mathbf{x}})$, the standard deviation $\left(\mathrm{s}_{\mathbf{x}}\right)$, the linear bivariate, and partial correlation coefficients ( $r$ ). The hypothesis of no differences in means was tested with the Wilcoxon Rank Sum Test for two samples. The hypothesis of no differences in proportions between two groups was tested with Fisher's exact test. The hypothesis of no differences in proportions when examining one group of subjects with two separate methods was tested with McNemar's test for correlated proportions (Remington and Schork 1970). Only two-tailed tests were used and differences were considered significant for $P$ values of 0.05 or less.

\section{Results}

\section{RESTING BLOOD PRESSURE}

The resting blood pressure in the hypertensive group $(\bar{x}=154 / 96 \mathrm{mmHg})$ was higher $(P<0.01)$ than in the reference group $(\bar{x}=123 / 77 \mathrm{mmHg})$ and in the infarct group $(\bar{x}=124 / 81 \mathrm{mmHg})$.

\section{ELECTROMECHANICAL INTERVAL (EMI)}

EMI was longer $(P<0.01)$ in the infarct group $(\overline{\mathrm{x}}=34 \mathrm{~ms})$ than in the reference group $(\overline{\mathrm{x}}=27 \mathrm{~ms})$, Table 1, and the proportion of patients in the infarct group with EMI $\geqslant 40 \mathrm{~ms}(25 \%)$ was also greater $(P<0.05)$ than in the reference group, 3 per cent (Fig. 3). The individual in the reference group who had EMI above $40 \mathrm{~ms}$ had a pathological a-wave $(\mathrm{a} / \mathrm{H}=33 \%)$ and angina pectoris with pathological $\mathrm{ST}$ and $\mathrm{T}$ changes on the electrocardiogram.

\section{ISOVOLUMETRIC CONTRACTION TIME (ICT)}

AND PRE-EJECTION PERIOD (PEP)

There were no significant differences in means between the groups with respect to ICT or PEP (Table 1).

ICT was negatively correlated to heart rate in the infarct group but not in the reference group. PEP was negatively correlated to heart rate in the hypertensive group but not in the reference or infarct groups. Trivariate regression analysis with resting diastolic blood pressure, ICT, and heart rate gave no significant correlation between diastolic blood pressure and ICT.

A linear correlation analysis between ICT and PEP gave $r=0.92$ in the reference group, $r=0.73$ in the infarct group, and $r=0.84$ in the hypertensive group.

\section{LEFT VENTRICULAR EJECTION TIME (LVET)}

LVET was negatively correlated to heart rate. The equation for the regression line in the reference group was $\mathrm{LVET}=390-1.51 \times$ heart rate.

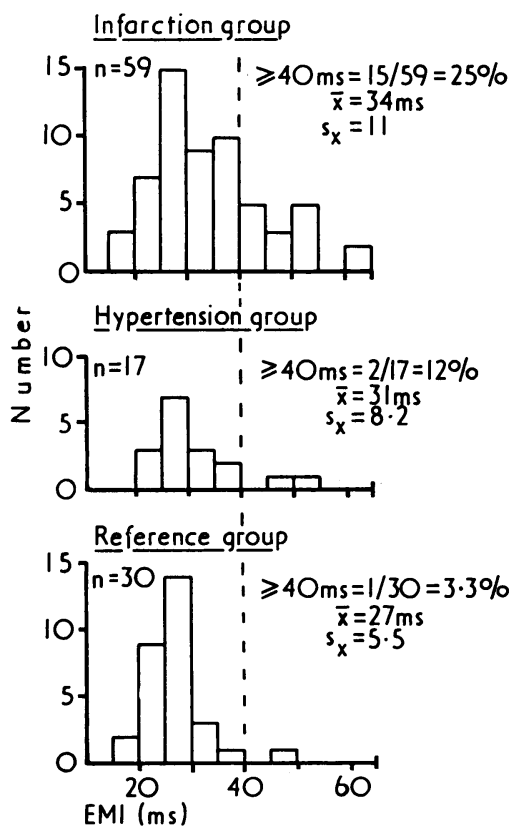

Fig. 3 Distribution of the electromechanical interval (EMI), and the proportion of subjects with $E M I \geqslant 40 \mathrm{~ms}$, the means $(\overline{\mathrm{x}})$, and the standard deviations $\left(\mathrm{s}_{\mathbf{x}}\right)$ in the 3 groups. 
There was no difference in the mean value for LVET between the three groups.

Trivariate regression analysis with resting systolic blood pressure, LVET, and heart rate gave no significant correlation between systolic blood pressure and LVET.
COMBINATION OF SYSTOLIC TIME INTERVALS Altogether 10 per cent of the patients in the infarct group and 11 per cent of the hypertensives had values of ICT $\geqslant 100 \mathrm{~ms}$ or LVET $\leqslant 90$ per cent which are not significantly higher than in the reference group, 3 per cent (Table 2). The dis-

Table 1 Time intervals, resting blood pressure, and heart rate in 3 groups

\begin{tabular}{|c|c|c|c|c|}
\hline \multicolumn{2}{|l|}{ Measurement } & \multirow{2}{*}{$\begin{array}{l}\text { Reference group } \\
36 \\
397 \\
23(17) \\
-0.68(P<0.001) \\
64\end{array}$} & \multirow{2}{*}{$\begin{array}{l}\text { Hypertensive group } \\
18 \\
397 \\
28(17) \\
-0.82(P<0.001) \\
64\end{array}$} & \multirow{2}{*}{$\begin{array}{l}\text { Infarct group } \\
61 \\
410 \\
30(17) \\
-0.82(P<0.001) \\
61\end{array}$} \\
\hline $\begin{array}{l}\mathrm{QA}_{2} \\
\text { (ms) } \\
\mathrm{HR}\end{array}$ & $\begin{array}{l}\mathbf{n} \\
\overline{\mathbf{x}} \\
\mathbf{8 x} \\
\mathbf{r} \\
\overline{\mathbf{x}}\end{array}$ & & & \\
\hline $\begin{array}{l}\text { EMI } \\
\text { (ms) } \\
\text { HR }\end{array}$ & $\begin{array}{l}\mathbf{n} \\
\overline{\mathbf{x}} \\
\mathbf{8 x} \\
\mathbf{r} \\
\overline{\mathbf{x}}\end{array}$ & $\begin{array}{l}30 \\
27 \\
5.5 \\
0 \cdot 40(P<0.05) \\
61\end{array}$ & $\begin{array}{l}17 \\
31 \\
8 \cdot 2 \\
0 \cdot 08(\mathrm{NS}) \\
64\end{array}$ & $\begin{array}{l}59 \\
34 \\
11 \\
0.33(P<0.05) \\
60\end{array}$ \\
\hline $\begin{array}{l}\text { PEP } \\
\text { (ms) } \\
\text { HR }\end{array}$ & $\begin{array}{l}\mathbf{n} \\
\overline{\mathbf{x}} \\
\mathbf{8} \mathbf{x} \\
\mathbf{r} \\
\overline{\mathbf{x}}\end{array}$ & $\begin{array}{l}36 \\
104 \\
13 \\
0 \cdot 00 \text { (NS) } \\
64\end{array}$ & $\begin{array}{l}18 \\
104 \\
13(12) \\
-0.52(P<0.05) \\
64\end{array}$ & $\begin{array}{l}61 \\
107 \\
13 \\
-0 \cdot 01 \text { (NS) } \\
61\end{array}$ \\
\hline $\begin{array}{l}\text { ICT } \\
\text { (ms) } \\
\text { HR }\end{array}$ & $\begin{array}{l}\mathbf{n} \\
\overline{\mathbf{x}} \\
\mathbf{8} \mathbf{x} \\
\mathbf{r} \\
\overline{\mathbf{x}}\end{array}$ & $\begin{array}{l}30 \\
77 \\
14 \\
-0 \cdot 14(n=16, N S) \\
62\end{array}$ & $\begin{array}{l}18 \\
74 \\
15 \\
-0.50(n=18, P<0.05) \\
64\end{array}$ & $\begin{array}{l}63 \\
73 \\
17(16) \\
-0.39(n=56, P<0.01) \\
61\end{array}$ \\
\hline $\begin{array}{l}\text { LVET } \\
\text { (ms) } \\
\text { HR }\end{array}$ & $\begin{array}{l}\mathbf{n} \\
\overline{\mathbf{x}} \\
\mathbf{8 x} \\
\mathbf{r} \\
\overline{\mathbf{x}}\end{array}$ & $\begin{array}{l}36 \\
293 \\
19(12) \\
-0.79(P<0.001) \\
64\end{array}$ & $\begin{array}{l}19 \\
293 \\
21(14) \\
-0.76(P<0.001) \\
64\end{array}$ & $\begin{array}{l}67 \\
300 \\
30(17) \\
-0.82(P<0.001) \\
62\end{array}$ \\
\hline ICT/LVET & $\begin{array}{l}n \\
\overline{\mathbf{x}} \\
\mathbf{s}_{\mathbf{x}} \\
\mathbf{r} \\
\overline{\mathbf{x}}\end{array}$ & $\begin{array}{l}30 \\
0 \cdot 263 \\
0 \cdot 056 \\
0 \cdot 24(n=16, N S) \\
62\end{array}$ & $\begin{array}{l}18 \\
0 \cdot 253 \\
0.049 \\
-0 \cdot 16(n=18, N S) \\
64\end{array}$ & $\begin{array}{l}63 \\
0.243 \\
0.061 \\
-0.06(n=56, N S) \\
61\end{array}$ \\
\hline $\begin{array}{l}\text { PEP/LVET } \\
\text { (ms) } \\
\text { HR }\end{array}$ & $\begin{array}{l}n \\
\overline{\mathbf{x}} \\
\mathbf{s} \mathbf{x} \\
\mathbf{r} \\
\overline{\mathbf{x}}\end{array}$ & $\begin{array}{l}36 \\
0.355 \\
0.052(0.050) \\
0.35(P<0.05) \\
64\end{array}$ & $\begin{array}{l}18 \\
0.357 \\
0.046 \\
-0.10(\mathrm{NS}) \\
64\end{array}$ & $\begin{array}{l}61 \\
0.356 \\
0.061(0.052) \\
0.53(P<0.001) \\
61\end{array}$ \\
\hline $\begin{array}{l}\mathrm{A}_{2} \mathrm{O} \\
(\mathrm{ms})\end{array}$ & $\begin{array}{l}n \\
\overline{\mathbf{x}} \\
\mathbf{s x} \\
\mathbf{r} \\
\overline{\mathbf{x}}\end{array}$ & $\begin{array}{l}29 \\
133 \\
9 \cdot 0 \\
0 \cdot 09 \\
61\end{array}$ & $\begin{array}{l}18 \\
153 \\
24(22) \\
-0.46(P<0.05) \\
65\end{array}$ & $\begin{array}{l}65 \\
160 \\
21(17) \\
-0.43(P<0.001) \\
61\end{array}$ \\
\hline $\begin{array}{l}\text { Resting SBP } \\
\text { (mmHg) } \\
\text { Resting DBP } \\
\text { (mmHg) } \\
\text { Resting HR }\end{array}$ & $\begin{array}{l}n \\
\overline{\mathbf{x}} \\
\mathbf{8 x} \\
\overline{\mathbf{x}} \\
\mathbf{8 x} \\
\overline{\mathbf{x}} \\
\mathbf{8 x}\end{array}$ & $\begin{array}{r}32 \\
123 \\
13 \\
77 \\
10 \\
60 \\
8\end{array}$ & $\begin{array}{r}19 \\
154 \\
23 \\
96 \\
15 \\
61 \\
8\end{array}$ & $\begin{array}{r}67 \\
124 \\
17 \\
81 \\
10 \\
61 \\
12\end{array}$ \\
\hline
\end{tabular}

The correlation coefficients ( $r$ ) between the different time intervals and heart rate are given together with the standard deviation around the regression line (in brackets after the sx). For correlation analysis between ICT and ICT/LVET, respectively, and heart rate the heart rate in the hypertension group was taken from the carotid pulse tracing (abbreviations: see Methods). 
crimination was not improved if the variable ICT/LVET was added and no patient with normal values for ICT, LVET, or ICT/LVET had an abnormal PEP/LVET value. There were no significant differences in means between the groups with respect of ICT/LVET or PEP/LVET (Table 1).

\section{PRESSURE RISE VELOCITY AND A/H RATIO}

Fig. 4 shows on the horizontal axis the $\mathrm{a} / \mathrm{H}$ ratio from the apex cardiogram and on the vertical axis the pressure rise velocity in the left ventricle calculated by dividing the diastolic blood pressure at

Table 2 Proportion of subjects with isovolumetric contraction time ICT $\geqslant 100 \mathrm{~ms}$, left ventricular ejection time LVET $\leqslant 90$ per cent, and ICT/LVET $>0.35$ in the 3 groups

\begin{tabular}{lllllll}
\hline & $\begin{array}{l}\text { Reference } \\
\text { group }\end{array}$ & \multicolumn{2}{l}{$\begin{array}{l}\text { Hypertensive } \\
\text { group }\end{array}$} & $\begin{array}{l}\text { Infarct } \\
\text { group }\end{array}$ \\
& $n$ & $\%$ & $n$ & $\%$ & $n$ & $\%$ \\
\hline ICT $\geq 100 \mathrm{~ms}$ & $1 / 30$ & 3 & $1 / 18$ & 6 & $4 / 63$ & 6 \\
LVET $\leq 90 \%$ & $0 / 36$ & 0 & $1 / 19$ & 5 & $4 / 67$ & 6 \\
ICT $/$ LVET $>0.35$ & $1 / 30$ & 3 & $1 / 18$ & 6 & $2 / 63$ & 3 \\
Cumulative total & $1 / 36$ & 3 & $2 / 19$ & 11 & $7 / 67$ & 10 \\
\hline
\end{tabular}

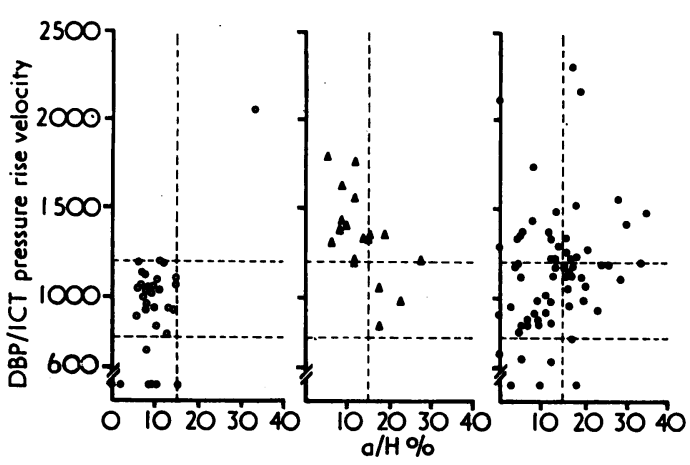

Fig. 4 Distribution of resting diastolic blood pressure/isovolumetric contraction time (DBP/ICT) and $a / H$ ratio from the apex cardiogram and the relation between these variables in the 3 groups. Left: Reference group $(n=36), a / H>15 \%=2 / 32=6 \%$. DBP $/ I C T$ $\leqslant 775 \mathrm{mmHg} / \mathrm{s}=1 / 26=4 \% ; \geqslant 1200 \mathrm{mmHg} / \mathrm{s}=1 / 26=$ 4\%. Middle: Hypertension group $(n=19), a / H$ $>15 \%=7 / 18=39 \% . D B P / I C T,-, \geqslant 1200 \mathrm{mmHg} / \mathrm{s}=$ $12 / 18=67 \%$. Right: Infarction group $(n=67), a / H$ $>15 \%=29 / 66=44 \% . D B P / I C T \leqslant 775 \mathrm{mmHg} / \mathrm{s}=$ $4 / 63=6 \%, \geqslant 1200 \mathrm{mmHg} / \mathrm{s}=24 / 63=38 \%$. Note that only one infarcted patient had both DBP/ICT $<775 \mathrm{mmHg} / \mathrm{s}$ and $\mathrm{a} / \mathrm{H}$ ratio $>15$ per cent concomitantly, and that the $a / H$ ratio discriminates better between the reference and infarct group than does a shortened $D B P / I C T$. rest by the ICT. An abnormal a/H ratio was found in 39 per cent in the hypertensives and 44 per cent in the infarct group, which was more $(P<0.05$, $\mathrm{P}<0.01$, respectively) than in the reference group $(6 \%)$.

Only 4 infarct patients $(6 \%)$ had pressure rise velocities below $775 \mathrm{mmHg} / \mathrm{s}$. Only one patient had an abnormal $\mathrm{a} / \mathrm{H}$ ratio simultaneously with a pressure rise velocity below $775 \mathrm{mmHg} / \mathrm{s}$.

The mean pressure rise velocity was higher $(P<0.01)$ in the hypertensive group $(\bar{x}=1323$ $\mathrm{mmHg} / \mathrm{s})$ than in the reference group $(\overline{\mathrm{x}}=1044 \mathrm{~mm}$ $\mathrm{Hg} / \mathrm{s}$ ). In the infarct group the mean value was $1168 \mathrm{mmHg} / \mathrm{s}$. Sixty-seven per cent of the men in the hypertensive group and 38 per cent of the infarct patients had pressure rise velocities $\geqslant 1200$ $\mathrm{mmHg} / \mathrm{s}$, which was more $(\mathrm{P}<0.01)$ than in the reference group $(4 \%)$. When infarct patients who were taking digitalis or $\beta$-blockers were excluded from this analysis 34 patients remained. Thirty-two per cent of these patients showed values of pressure rise velocity above $1200 \mathrm{mmHg} / \mathrm{s}$, which was still more $(P<0.02)$ than in the reference group. The $\mathrm{a} / \mathrm{H}$ ratio for these patients was 13.5 per cent, which

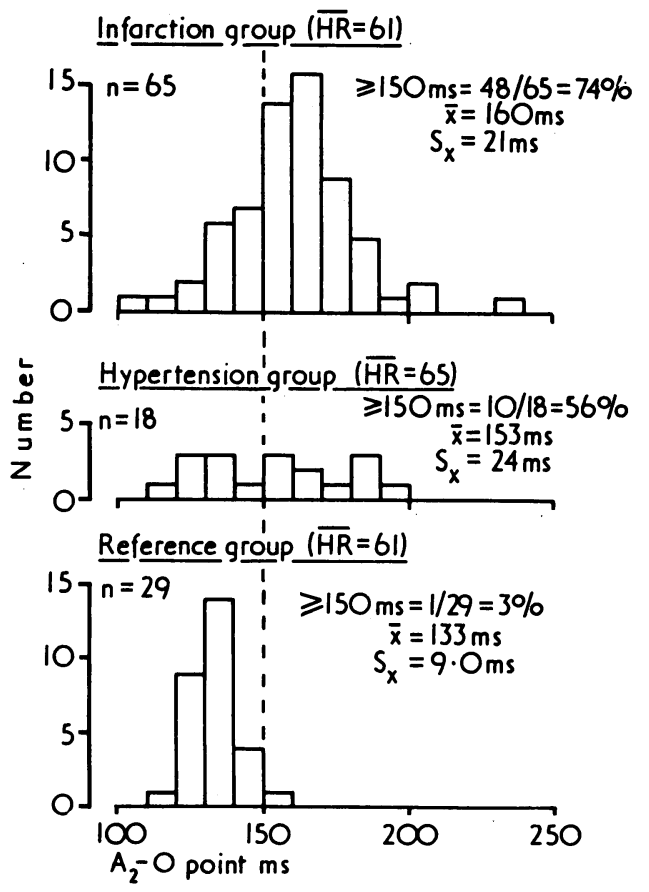

Fig. 5 Distribution of the interval between the aortic component of the second heart sound and the O-point in the apex cardiogram $\left(A_{2} O\right)$, and the proportion of subjects with $A_{2} O \geqslant 150$ ms, the means $(\overline{\mathrm{x}})$, and the standard deviation $\left(\mathrm{s}_{\mathrm{x}}\right)$ in the 3 groups. 
was not significantly higher than for infarct patients who were not receiving digitalis or $\beta$-blockers $(\overline{\mathrm{x}}=10.9 \%)$ and who had pressure rise velocities $<1200 \mathrm{mmHg} / \mathrm{s}$.

\section{$\mathrm{A}_{2} \mathrm{O}$ INTERVAL}

The $\mathrm{A}_{2} \mathrm{O}$ interval was longer $(\mathrm{P}<0.01)$ in both the hypertensive group $(\overline{\mathbf{x}}=153 \mathrm{~ms})$ and the infarct group $(\overline{\mathbf{x}}=160 \mathrm{~ms})$ than in the reference group $(\overline{\mathrm{x}}=133 \mathrm{~ms})$. The proportion of patients with $\mathrm{A}_{2} \mathrm{O}$ interval $\geqslant 150 \mathrm{~ms}$ was also higher $(P<0.01)$ in the hypertensive group (56\%) and the infarct group $(74 \%)$ than in the reference group, 3 per cent (Fig. 5). The man in the reference group with a prolonged $\mathrm{A}_{2} \mathrm{O}$ interval had the highest diastolic pressure in the reference group at the screening examination $(110 \mathrm{mmHg})$, but the pressure was normal $(89 \mathrm{mmHg})$ when the apex cardiogram was registered. Eighty-eight per cent of all subjects in the hypertensive and infarct groups with prolonged $\mathrm{A}_{2} \mathrm{O}$ interval also had prolongation of the interval between $A_{2}$ and 90 per cent amplitude reduction of the apex cardiogram.

The $\mathrm{A}_{2} \mathrm{O}$ interval was negatively correlated to heart rate in the infarct group $(r=-0.43, n=65$, $P<0.01)$ and in the hypertensive group $(r=-0.46$, $\mathrm{n}=18, \mathrm{P}<0.05)$ but not in the reference group $(\mathrm{r}=0 \cdot 09)$. Trivariate regression analysis with resting systolic blood pressure, $\mathrm{A}_{2} \mathrm{O}$, and heart rate gave a significant positive correlation between resting systolic blood pressure and $\mathrm{A}_{2} \mathrm{O}$ in the hypertensive group, $r=0.56(P<0.05)$ but not in the reference or infarct groups. The corresponding analysis for diastolic resting blood pressure gave a significant correlation in the infarct group, $r=0.27(P<0.05)$ but not in the hypertensive or reference groups.

\section{TIME INTERVALS IN PATIENTS WITH AND}

WITHOUT DIGITALIS THERAPY

The mean value for LVET per cent was lower $(\mathrm{P}<0.01)$ in patients receiving digitalis $(\overline{\mathbf{x}}=98 \%$, $\left.s_{x}=5 \cdot 7, n=21\right)$ than in the infarct patients not on digitalis $\left(\bar{x}=103 \%, s_{x}=6 \cdot 2, n=35\right)$, but there were no significant differences in means with respect to ICT, PEP, ICT/LVET, the $\mathrm{A}_{2} \mathrm{O}$ interval, resting blood pressure, or heart rate.

PROGNOSIS IN INFARCT GROUP IN RELATION TO SYSTOLIC TIME INTERVALS

Of the 14 patients in the infarct group who exhibited cardiogenic shock or left ventricular failure during the acute illness, $3(21 \%)$ had pathological systolic time intervals 3 months after onset of infarction. Of the 67 infarct patients, $9(13 \%)$ died within 2 years after the non-invasive examination and 3 of these (33\%) had had pathological systolic time intervals at the non-invasive investigation (LVET $=90 \%$, and ICT $=101 \mathrm{~ms}$ and $102 \mathrm{~ms}$, respectively).

\section{Discussion}

When cardiac function has been studied more precisely in hypertensives or infarct patients this has previously been done in small selected groups of hospital patients, the control groups also necessarily being small and selected. To avoid the drawbacks entailed by selection the groups in the present study comprised random population samples. This definition of the groups studied makes it possible to generalise about the results. The results showed that only the electromechanical interval, pressure rise velocity, and $\mathrm{A}_{2} \mathrm{O}$ point interval were useful discriminants between the three groups. It is clear that invasive assessment of left ventricular function would have yielded interesting data for correlation with the non-invasive data. Catheterisation and angiocardiography were, however, not performed, as it was not considered ethically justifiable to perform these invasive investigations in the symptomless subjects in the reference and hypertensive groups derived by screening, or in several of the infarct patients. Several studies of the correlation between non-invasive variables and invasive indices of left ventricular function have been carried out by other authors in selected groups of subjects (Voigt and Friesinger, 1970; Martin et al., 1971; Van de Werf et al., 1975).

Comparison of the mean values for systolic time intervals in the infarct and hypertensive groups with those in the reference group showed that the pattern was not that which could be expected when left ventricular function was impaired. The prognostic value was difficult to assess since the number of infarct patients who died during follow-up was low and very few infarct patients had divergent systolic time intervals. The prognostic value of the combined non-invasive data is discussed elsewhere, the systolic time intervals having been found in several cases to be quite normal despite the fact that other non-invasive data suggested considerable impairment of left ventricular function (Wikstrand, 1976). Furthermore, 3 of the 4 infarct patients with low LVET were taking digitalis. Digitalis shortens LVET even in patients with heart failure (Weissler and Schoenfeld, 1970) and the significance of a shortened LVET is thus difficult to assess in a patient taking digitalis.

A quarter of the patients in the infarct group had prolonged EMI values, indicating delayed start of the systolic contraction of the left ventricle (Willems et al., 1971; Manolas et al., 1975). An 
individual with apparently normal impulse conduction on the electrocardiogram may thus have a prolonged PEP, owing to prolongation of the EMI, which may be erroneously interpreted as indicating a prolonged isovolumetric contraction time. Correlation analysis also showed that a PEP value predicted an ICT value with great uncertainty in the infarct group. These factors and our results make it unlikely that PEP will be a sensitive index of impaired left ventricular function. This is not to be wondered at since even complicated and sophisticated invasive isovolumetric indices of left ventricular function have proved to be of doubtful value (Peterson et al., 1974; Kreulen et al., 1975).

It has been found that the diagnostic value of the PEP increases when it is combined with invasively measured pulmonary capillary venous pressure and non-invasively measured diastolic arterial blood pressure for calculation of the pressure rise velocity in the left ventricle (Agress et al., 1972; Diamond et al., 1972). Combination of ICT and resting diastolic arterial blood pressure did not improve discrimination in our study as regards impaired left ventricular function. Correction for the end-diastolic pressure in the left ventricle could not be done, however, as invasive measurements were not performed. One of the reasons why Fig. 4 was constructed was to obtain an indirect measure of preload, the $\mathrm{a} / \mathrm{H}$ ratio, in relation to pressure rise velocity. Only one infarct patient, however, had an abnormal $\mathrm{a} / \mathrm{H}$ ratio and a reduced pressure rise velocity concomitantly, which should be a combination indicative of substantially impaired left ventricular function. On the contrary the results regarding pressure rise velocity may be interpreted as showing that ventricular contraction was more powerful in several infarct patients compared with the individuals in the reference group. This finding could not be explained by digitalis therapy. Nor could it be explained by differences in the enddiastolic pressure, as judged from the $\mathrm{a} / \mathrm{H}$ ratio from the apex cardiogram. Reservation must, however, be made for the fact that patients with greatly increased end-diastolic pressure may have a normal a-wave in the apex cardiogram (Voigt and Friesinger, 1970). Infarct patients exhibit signs of increased sympathetic activity in the acute phase, which can be reduced by $\beta$-blockade (Waagstein et al., 1974). Our data regarding pressure rise velocity suggest that the sympathetic activity may be raised in these patients at rest even long after the acute phase. The results showed that the pressure rise velocity during the isovolumetric contraction was also higher in hypertensives than in normotensive individuals. This was at least partly related to left ventricular hypertrophy as judged by orthogonal electrocardiogram (Wikstrand, 1976).

It has been claimed that arterial pressure must be included as a prime determinant of LVET along with stroke volume, heart rate, and inotropic state in man (Shaver et al., 1968). Our results accord, however, with the findings of Weissler et al. (1969), that among patients with chronic arterial hypertension and minimal functional impairment no independent effect of arterial pressure on the systolic time intervals or PEP/LVET ratio can be shown. Braunwald et al. (1958) have also shown that when heart rate and stroke volume were maintained constant, increasing aortic pressure did not affect the duration of ejection except at very high mean aortic pressure (175 to $200 \mathrm{mmHg}$ ). Cardiac output was not measured in our study. At this stage of hypertension cardiac output is, however, known to be raised or normal (Lund-Johansen, 1967). Since the mean values for LVET were identical in the hypertensive and reference groups, and the pulse pressure was higher in the hypertensive group the figures imply increased rate of ejection in the hypertensive group.

The results regarding the systolic time intervals give the impression that the hypertensive group as well as the infarct group were homogeneous. It is, however, obvious from other non-invasive results in these groups that the nature as well as the severity of heart involvement varies considerably within the groups (Berglund et al., 1976; Wikstrand, 1976; Wikstrand et al., 1976) though the systolic time intervals failed to show this. Signs of systolic left ventricular functional impairment appear at a late stage since the altered filling pattern during diastole, with powerful atrial contractions and increased diastolic filling and hypertrophy of the left ventricle, may for a long time compensate for the impaired left ventricular function, at least during rest (Rackley et al., 1970; Dodge, 1973). When impairment of the left ventricular function is studied at an early stage interest should, therefore, be concentrated mainly on diastole. Several methods are required to identify the majority of patients with left ventricular dysfunction and the systolic time intervals are only a small part of the whole picture. This is also evident from the other non-invasive results in the infarct group (Wikstrand, 1976) and from the fact that the $\mathrm{a} / \mathrm{H}$ ratio discriminated well between the groups, unlike a decreased pressure rise velocity (Fig. 4).

The $\mathrm{A}_{2} \mathrm{O}$ interval was significantly prolonged in more than 50 per cent of the hypertensives and more than 70 per cent of the patients in the infarct group. The finding that not only the $\mathrm{A}_{2} \mathrm{O}$ interval but also the interval between $A_{2}$ and a point on the diastolic downstroke of the apex cardiogram defined 
by the total amplitude of the apex cardiogram discriminates well between the groups, supports the postulate that this phase of the cardiac cycle really was prolonged. One of the reasons why such a striking finding has been so little studied may be the use of transducers with too short low frequency time constants in many previous studies, since transducers with short low frequency time constants not only shorten the $\mathrm{A}_{2} \mathrm{O}$ interval but also tend to smooth out differences between an individual with a prolonged, and a person with a normal, $\mathrm{A}_{2} \mathrm{O}$ interval (Wikstrand et al., 1977).

The prolongation of the $\mathrm{A}_{2} \mathrm{O}$ interval in the infarct group could not be explained by differences in heart rate or arterial blood pressure since the mean values for heart rate and blood pressure were almost identical with those in the reference group. It is difficult to suggest, on the basis of the findings in this study, any form of correction procedure for the $\mathrm{A}_{2} \mathrm{O}$ interval for heart rate and blood pressure for routine clinical use, since no significant correlations were found in the reference group and the correlations found in the infarct and hypertensive groups were weak. Nor is it possible to determine the extent to which the weak correlations found between $\mathrm{A}_{2} \mathrm{O}$ and arterial blood pressure in the hypertensive group were the result of morphological changes owing to hypertension and not the result of the actual blood pressure level. Prolongation of the $\mathrm{A}_{2} \mathrm{O}$ interval could not be related to hypertension in the infarct group (Wikstrand, 1976). It has been shown that the $\mathrm{A}_{2} \mathrm{O}$ interval is prolonged by infusion of ouabain (Benchimol and Ellis, 1967). The $\mathrm{A}_{2} \mathrm{O}$ difference does not seem to have been influenced by digitalis therapy in our study however.

Previously the $\mathrm{A}_{2} \mathrm{O}$ interval has often been used as a synonym for the isovolumetric relaxation time (Benchimol and Ellis, 1967; Harmjanz et al., 1971). The $\mathrm{A}_{2} \mathrm{O}$ interval, however, comprises two phases, the relaxation phase and a period of the early filling phase of the left ventricle. Since the mean value for this filling phase has been calculated to be $50 \mathrm{~ms}$ (Prewitt et al., 1975), the latter may in certain cases represent about one-third of the $\mathrm{A}_{2} \mathrm{O}$ interval.

The parallel-coupled elastic elements may, if rigid, owing to reduced elasticity because of, for example, collage deposits or hypertrophy, recover more slowly, thus prolonging the relaxation period (Harrison et al., 1964). In addition, relaxation is an energy-demanding process (Langer, 1968; Meerson and Kapelko, 1975). If in ischaemia the supply and demand of calcium or ATP are barely balanced during the systolic contraction, a relative deficiency of ATP, with delayed inactivation of calcium might arise, leading to delayed relaxation (Fogelman et al., 1972; Kovick et al., 1975). It has also been found that the contraction phase and the relaxation phase can be influenced partly independently of one another (Parmley and Sonnenblick, 1969; Cohn et al., 1972; Meerson and Kapelko, 1975). The findings in our study in both the hypertensive and the infarct groups of increased pressure rise velocity, and delayed $O$ point in the apex cardiogram concomitantly thus do not seem contradictory. Further studies are required to elucidate the reasons for the prolongation of the $\mathrm{A}_{2} \mathrm{O}$ interval in hypertensives and in postinfarction patients.

This study was supported by grants from the Swedish Medical Research Council, the Swedish National Association against Heart and Chest Diseases, and the Bank of Sweden Tercentenary Foundation.

\section{References}

Agress, C. M., Wegner, S., Forrester, J. S., Chatterjee, K., Parmley, W. W., and Swan, H. J. C. (1972). An indirect method for evaluation of left ventricular function in acute myocardial infarction. Circulation, 46, 291-297.

Ahmed, S. S., Levinson, G. E., Schwartz, C. J., and Ettinger, P. O. (1972). Systolic time intervals as measures of the contractile state of the left ventricular myocardium in man. Circulation, 46, 559-571.

Baragan, J., Fernandez-Caamano, F., Sozutek, Y., Coblence, B., and Lenègre, J. (1968). Chronic left complete bundlebranch block. British Heart fournal, 30, 196-202.

Benchimol, A., and Ellis, J. G. (1967). A study of the period of isovolumetric relaxation in normal subjects and in patients with heart disease. American fournal of Cardiology, 19, 196-206.

Berglund, G., Wikstrand, J., Wallentin, I., and Wilhelmsen, L. (1976). Sodium excretion and sympathetic activity in relation to severity of hypertensive disease. Lancet, 1, 324328.

Braunwald, E., Sarnoff, S. J., and Stainsby, W. N. (1958). Determinants of duration and mean rate of ventricular ejection. Circulation Research, 6, 319-325.

Cohn, P. F., Liedtke, A. J., Serur, J., Sonnenblick, E. H., and Urschel, C. W. (1972). Maximale rate of pressure fall (peak negative $\mathrm{dP} / \mathrm{dt}$ ) during ventricular relaxation. Cardiovascular Research, 6, 263-267.

Diamond, G., Forrester, J. S., Chatterjee, K., Wegner, S., and Swan, H. J. C. (1972). Mean electromechanical $\Delta P / \Delta t$. An indirect index of the peak rate of rise of left ventricular pressure. American fournal of Cardiology, 30, 338-342.

Dodge, H. T. (1973). Haemodynamic aspects of cardiac failure. In The Myocardium: Failure and Infarction, p. 70. Ed. by E. Braunwald. HP Publishing Co., New York.

Elmfeldt, D., Wilhelmsen, L., Tibblin, G., Vedin, J. A., Wilhelmsson, C.-E., and Bengtsson, C. (1975a). Registration of myocardial infarction in the city of Göteborg, Sweden. Fournal of Chronic Diseases, 28, 173-186.

Elmfeldt, D., Wilhelmsen, L., Tibblin, G., Vedin, J. A., Wilhelmsson, C.-E., and Bengtsson, C. (1975b). A postmyocardial infarction clinic in Göteborg, Sweden. Acta Medica Scandinavica, 197, 497-502. 
Fogelman, A. M., Abbasi, A. S., Pearce, M. L., and Kattus, A. A. (1972). Echocardiographic study of the abnormal motion of the posterior left ventricular wall during angina pectoris. Circulation, 46, 905-913.

Garrard, C. L., Weissler, A. M., and Dodge, H. T. (1970). The relationship of alterations in systolic time intervals to ejection fraction in patients with cardiac disease. Circulation, 42, 455-462.

Harmjanz, D., Böttcher, D., and Schertlein, G. (1971). Correlations of electrocardiographic pattern, shape of ventricular septum, and isovolumetric relaxation time in irregular hypertrophic cardiomyopathy (obstructive cardiomyopathy). British Heart fournal, 33, 928-937.

Harrison, T. R., Dixon, K., Russell, R. O., Bidwai, P. S., and Coleman, H. N. (1964). The relation of age to the duration of contraction, ejection and relaxation of the normal human heart. American Heart fournal, 67, 189199.

Hodges, M., Halpern, B. L., Friesinger, G. C., and Dagenais, G. R. (1972). Left ventricular pre-ejection period and ejection time in patients with acute myocardial infarction. Circulation, 45, 933-942.

Johnson, J. M., Siegel, W., and Blomqvist, G. (1971). Characteristics of transducers used for recording the apexcardiogram. Fournal of Applied Physiology, 31, 796-800.

Kovick, R. B., Fogelman, A. M., Abbasi, A. S., Peter, J. B., and Pearce, M. L. (1975). Echocardiographic evaluation of posterior left ventricular wall motion in muscular dystrophy. Circulation, 52, 447-454.

Kreulen, T. H., Bove, A. A., McDonough, M. T., Sands, M. J., and Spann, J. F. (1975). The evaluation of left ventricular function in man. A comparison of methods. Circulation, 51, 677-688.

Kumar, S., and Spodick, D. H. (1970). Study of the mechanical events of the left ventricle by atraumatic techniques: comparison of methods of measurement and their significance. American Heart fournal, 80, 401-413.

Langer, G. A. (1968). Ion fluxes in cardiac excitation and contraction and their relation to myocardial contractility. Physiological Reviews, 48, 708-757.

Lund-Johansen, P. (1967). Hemodynamics in early essential hypertension. Acta Medica Scandinavica, Suppl. 482.

Manolas, J., Rutishauser, W., Wirz, P., and Arbenz, U. (1975). Time relation between apex cardiogram and left ventricular events using simultaneous high-fidelity tracings in man. British Heart fournal, 37, 1263-1267.

Martin, C. E., Shaver, J. A., Thompson, M. E., Reddy, P. S., and Leonard, J. J. (1971). Direct correlation of external systolic time intervals with internal indices of left ventricular function in man. Circulation, 44, 419-431.

Meerson, F. Z., and Kapelko, V. I. (1975). The significance of the inter-relationship between the intensity of the contractile state and the velocity of relaxation in adapting cardiac muscle to function at high work loads. Fournal of Molecular and Cellular Cardiology, 7, 793-806.

Parker, M. E., and Just, H. G. (1974). Systolic time intervals in coronary artery disease as indices of left ventricular function: fact or fancy? British Heart fournal, 36, 368-376.

Parmley, W. W., and Sonnenblick, E. H. (1969). Relation between mechanics of contraction and relaxation in mammalian cardiac muscle. American fournal of Physiology, 216, 1084-1091.

Peterson, K. L., Skloven, D., Ludbrook, P., Uther, J. B., and Ross, J. (1974). Comparison of isovolumetric and ejection phase indices of myocardial performance in man. Circulation, 49, 1088-1101.

Prewitt, T., Gibson, D., Brown, D., and Sutton, G. (1975). The 'rapid filling wave' of the apex cardiogram. British Heart fournal, 37, 1256-1262.

Rackley, C. E., Hood, W. P., Rolett, E. L., and Young, D. T. (1970). Left ventricular end-diastolic pressure in chronic heart disease. American fournal of Medicine, 48, 310-319.

Remington, R., and Schork, M. A. (1970). Statistics with Applications to Biological and Health Sciences. PrenticeHall, Englewood Cliffs, New Jersey.

Shaver, J. A., Kroetz, F. W., Leonard, J. J., and Paley, H. W. (1968). The effect of steady-state increases in systemic arterial pressure on the duration of left ventricular ejection time. Fournal of Clinical Investigation, 47, 217-230.

Tavel, M. E., Campbell, R. W., Feigenbaum, H., and Steinmetz, E. F. (1965). The apex cardiogram and its relationship to haemodynamic events within the left heart. British Heart fournal, 27, 829-839.

van de Werf, F., Piessens, J., Kesteloot, H., and de Geest, H. (1975). A comparison of systolic time intervals derived from the central aortic pressure and from the external carotid pulse tracing. Circulation, 51, 310-316.

Voigt, G. C., and Friesinger, G. C. (1970). The use of apex cardiography in the assessment of left ventricular diastolic pressure. Circulation, 41, 1015-1024.

Waagstein, F., Hjalmarson, A. C., and Wasir, H. S. (1974). Apex cardiogram and systolic time intervals in acute myocardial infarction and effects of practolol. British Heart fournal, 36, 1109-1121.

Weissler, A. M., Harris, W. S., and Schoenfeld, C. D. (1969). Bedside technics for the evaluation of ventricular function in man. American fournal of Cardiology, 23, 577-583.

Weissler, A. M., and Schoenfeld, C. D. (1970). Effect of digitalis on systolic time intervals in heart failure. American fournal of the Medical Sciences, 259, 4-20.

Wikstrand, J. (1976). Non-invasive assessment of cardiac function. Studies in normotensive and hypertensive 50-yearold men and male infarction patients aged 48-57. Thesis Göteborg, Sweden. (Available on request.)

Wikstrand, J., Berglund, G., Wilhelmsen, L., and Wallentin, I. (1976). Orthogonal electrocardiogram, apex cardiogram, and atrial sound in normotensive and hypertensive 50-yearold men. British Heart fournal, 38, 779-789.

Wikstrand, J., Nilsson, K., and Wallentin, I. (1977). Distortion of non-invasive cardiac pulse curves. A capillarydamped pick-up and a calibration unit for apex cardiograms and other pulse curves. British Heart fournal, 39, 995-1005.

Wilhelmsen, L., Berglund, G., and Werkö, L. (1973). Prevalence and management of hypertension in a general population sample of Swedish men. Preventive Medicine, 2, 57-66.

Wilhelmsen, L., Tibblin, G., and Werkö, L. (1972). A primary preventive study in Gothenburg, Sweden. Preventive Medicine, 1, 153-160.

Willems, J. L., de Geest, H., and Kesteloot, H. (1971). On the value of apex cardiography for timing intracardiac events. American fournal of Cardiology, 28, 59-66.

Requests for reprints to Dr John Wikstrand, Department of Clinical Physiology, Sahlgren's Hospital, S-413 45 Göteborg, Sweden. 